University of Nebraska - Lincoln

DigitalCommons@University of Nebraska - Lincoln

2012

\title{
Nocturnal Activity of Nesting Shrubland and Grassland Passerines
}

\author{
Christy Slay \\ University of Arkansas, cslay@walton.uark.edu \\ Kevin Ellison \\ University of Wisconsin, kellison@wcs.org \\ C.A. Ribic \\ Wisconsin Cooperative Wildlife Research Unit, caribic@wisc.edu \\ Kimberly Smith \\ University of Arkansas, kgsmith@uark.edu \\ Carolyn Schmitz \\ University of Wisconsin, cmschmitz2@wisc.edu
}

Follow this and additional works at: https://digitalcommons.unl.edu/usgsnpwrc

Part of the Other International and Area Studies Commons

Slay, Christy; Ellison, Kevin; Ribic, C.A.; Smith, Kimberly; and Schmitz, Carolyn, "Nocturnal Activity of Nesting Shrubland and Grassland Passerines" (2012). USGS Northern Prairie Wildlife Research Center. 259.

https://digitalcommons.unl.edu/usgsnpwrc/259

This Article is brought to you for free and open access by the US Geological Survey at DigitalCommons@University of Nebraska - Lincoln. It has been accepted for inclusion in USGS Northern Prairie Wildlife Research Center by an authorized administrator of DigitalCommons@University of Nebraska - Lincoln. 


\title{
Nocturnal Activity of Nesting Shrubland and Grassland Passerines
}

\author{
Christy M. Slay, Kevin S. Ellison, Christine A. Ribic, \\ Kimberly C. Smith, and Carolyn M. Schmitz
}

\begin{abstract}
Nocturnal behaviors and sleep patterns of nesting passerines remain largely undocumented in the field and are important to understanding responses to environmental pressures such as predation. We used nocturnal video recordings to describe activity and quantify behaviors of females with nestlings of four shrubland bird species and three grassland bird species ( $n=19$ nests). Among the shrubland birds, Blue-winged Warbler (Vermivora pinus), Prairie Warbler (Setophaga discolor), and Indigo Bunting (Passerina cyanea) returned to the nest for the night at the same time, around sunset. Among the grassland birds, Eastern Meadowlark (Sturnella magna) returned the earliest before sunset and Grasshopper Sparrow (Ammodramus savannarum) returned the latest after sunset. All species exhibited "back sleep" with the bill tucked under scapular feathers, and individuals awoke frequently for vigils or "peeks" at their
\end{abstract}

surroundings. Sleep of all species was disrupted by nestling activity. Average duration of sleep bouts varied from 6 min (Grasshopper Sparrow) to 28 min (Blue-winged Warbler; Field Sparrow, Spizella pusilla). Mean overnight duration on the nest varied from $6.4 \mathrm{hr}$ (Field Sparrow) to $8.8 \mathrm{hr}$ (Indigo Bunting). On average, adults woke in the morning (the last waking before departing the nest) 20-30 min before sunrise. The first absence from the nest in the morning was short for all species, and nestlings were fed within $12 \mathrm{~min}$ of a parent's departure. Our study highlights the need for further video research on sleep patterns of nesting birds in the field to better understand basic natural history, energetic cost-benefits of sleep, and behavioral adaptations to environmental pressures.

Key Words: avian behavior, camera, night, sleep, video surveillance, vigilant. nformation on the behavioral ecology of breeding passerines (e.g., Poole 2005) is biased toward activities that occur during the daylight hours. Even early studies that used sensors in nests had this bias; for example, a study by Weeden (1966) was conducted at a latitude seasonally lacking darkness and Kendeigh (1952) focused on measurements made during the day. The paucity of information available on nocturnal behavior of nesting passerines may reflect logistical constraints of working in the dark as well as a lack of appreciation for the existence or relevance

Slay, C. M., K. S. Ellison, C. A. Ribic, K. G. Smith, and C. M. Schmitz. 2012. Nocturnal activity of nesting shrubland and grassland passerines. Pp. 105-116 in C. A. Ribic, F. R. Thompson III, and P. J. Pietz (editors). Video surveillance of nesting birds. Studies in Avian Biology (no. 43), University of California Press, Berkeley, CA. 
of nighttime activity. Video surveillance systems remove the logistical constraints and facilitate research on passerine nesting behavior, particularly on behaviors that are difficult to observe directly such as sleep.

Relatively little is known about nocturnal nesting behaviors of passerines in the wild, even with recent advances in video technology. Weeden (1966) found that Tree Sparrows (Spizella arborea) incubated eggs for $5 \mathrm{hr}$ continuously during the overnight hours despite a lack of darkness. Kendeigh (1952) reported that House Wren (Troglodytes aedon) nocturnal attentiveness varied during the incubation and nestling stages. For the nestling stage, he found that House Wren and Song Sparrow (Melospiza melodia) females were present on the nest at night and that both species settled on the nest after sunset and became active before sunrise (Kendeigh 1952). Nolan (1978) documented that Prairie Warbler (Setophaga discolor) females, on average, returned to the nest for the night $29 \mathrm{~min}$ later and left 22 min earlier in the morning during the nestling stage than during the incubation stage. A study of Western Meadowlarks (Sturnella neglecta) using video surveillance found that females left the nest unattended at night $13 \%$ of the time during the nestling period (Powell et al., chapter 5, this volume). In these studies, the presence of adults was documented but sleep was not measured.

An animal is perhaps at its most vulnerable to risk of predation during sleep; therefore, individuals must balance their need for sleep with costs and benefits of other activities such as foraging, preening, or parental care (Lima et al. 2005, Roth et al. 2006). Sleeping birds are exposed to greater danger from predation if sleep and vigilance are trade-offs (Gauthier-Clerc et al. 2000). To reduce this risk, many bird species exhibit unihemispheric sleep with the head forward and only one eye open, a state documented in the laboratory, where half of the brain is asleep and the other half is in a semi-waking state of vigilance (Rattenborg et al. 1999, 2000; Fuchs et al. 2006, 2009). In daytime field studies, duck species on open water have a similar sleeping pattern, with alternating periods of eye closure and eye opening, the latter referred to as vigilant "peeks" or "scans" (Lendrem 1983, 1984; Gauthier-Clerc et al. 2000; Javurkova et al. 2011). Javurkova et al. (2011) video-recorded incubating female Mallards (Anas platyrhynchos) and found the females scanned their environment more frequently during the day than at night. They also found that incubating females increased vigilance with increasing vegetation cover on the side of the nest facing the female's open eye; however, female vigilance did not change with mean vegetation cover at the nest. These findings suggest trade-offs in vigilance based on light conditions and field of view of the scanning eye as well as trade-offs for detection of diurnal and nocturnal predators.

Laboratory studies found that most passerines exhibit both "front" sleep (defined as the head forward and eyes closed) and "back" sleep (defined as the head turned to one side and the bill tucked under or on the scapular feathers) (Amlaner and Ball 1983). A passerine exhibiting back sleep that moves its head for a "peek" or vigil is exhibiting a different behavior than that of a bird that scans with the head already forward and only one eye open. However, documentation of passerine sleep postures and other nocturnal behaviors is primarily from laboratory studies, includes few passerine species, and is not documented for breeding passerines in the field (Amlaner and Ball 1983; Fuchs et al. 2006, 2009; Wellmann and Downs 2009).

We video-recorded activity at nests of four shrubland and three grassland bird species for which nocturnal behaviors have not been described. Because information on nocturnal behaviors of passerines is especially rare at the nestling stage and one study of Indigo Buntings (Passerina cyanea) suggests females have a propensity for abandoning the nest if disturbed before the nestling stage (Thompson et al. 1999), we focused our efforts on nests containing nestlings. The purpose of this paper is to document nocturnal activity of adults with nestlings, including sleep postures, duration of sleep between "peeks" or vigils, and other behaviors at the nest from last arrival at night to first feeding of nestlings the following morning.

\section{METHODS}

Study Areas

Shrubland field sites were located in Southbury, Connecticut, at the Bent of the River Audubon Center. The two sites consist of 23 ha of experimentally managed, early successional vegetation termed conservation-managed fields; collectively, this is the largest privately managed shrubland 
in the state (Slay and Smith 2009). The dominant shrub species at these sites was the native, clonal gray dogwood (Cornus racemosa). Other less abundant woody species included black cherry (Prunus serotina), quaking aspen (Populus tremuloides), Eastern redcedar (Juniperus virginiana), multiflora rose (Rosa multiflora), Japanese barberry (Berberis thunbergii), blackberry/wineberry/dewberry (Rubus spp.), and autumn olive (Eleagnus umbellata). Common herbaceous species included goldenrod (Solidago spp.), black-eyed susan (Rudbeckia hirta), and bee balm (Monarda spp.). Native grass species included Indian grass (Sorghastrum spp.), little bluestem (Schizachyrium spp.), and big bluestem (Andropogon spp.). Of the four shrubland species we monitored, Blue-winged Warbler (Vermivora pinus) is the only ground nester. It typically selects nest sites in grass adjacent to a single shrub; the other three shrubland species nested $36-99 \mathrm{~cm}$ off the ground in 101-151-cm-tall shrubs.

Ground-nesting grassland birds were studied on sites in southwestern Wisconsin, near the town of Mount Horeb. The sites were remnant prairie and Conservation Reserve Program (CRP) fields planted with native warm-season grasses. The Wisconsin sites $(n=16$; range $=6.6-21.9 \mathrm{ha})$ were dominated by little bluestem, big bluestem, needle (porcupine) grass (Stipa spartea), Indian grass, side-oats grama (Bouteloua curtipendula), and panic grass (Panicum spp.), with relatively little woody vegetation. See Ellison and Ribic (chapter 12, this volume) for further details.

\section{Camera Deployment}

Shrubland nest activity was captured by wireless color cameras and receivers manufactured by First Alert ${ }^{\circledR}$ in Englewood, New Jersey, housed in protective plastic cylinders. Only nests in the nestling stage were filmed, as Thompson et al. (1999) found in their video study that Indigo Buntings are more sensitive than Field Sparrows to human disturbance and prone to abandoning nests in the nestbuilding, egg-laying, and early incubation stages. Cameras were $325 \mathrm{~cm}^{3}$ and contained six infrared light-emitting diodes (LEDs) to illuminate the nest both day and night; a 2.4-Ghz wireless transmitter sent images to be recorded. Cameras were mounted in cut saplings of gray dogwood or black cherry for nests in shrubs and mounted on $60-\mathrm{cm}$ rebar for ground nests. Each nest had a camera placed $30-40 \mathrm{~cm}$ from the nest rim. The field of view from camera to nest area was $450-600 \mathrm{~cm}^{2}$, depending on where the camera was placed due to surrounding vegetation. Cameras recorded up to 36 frames per sec onto VHS tape and tapes were changed every $24 \mathrm{hr}$. Cameras, receivers, and VCRs were powered by marine batteries. Solar trickle chargers were used to extend the power supply of batteries. Batteries were changed in the field every three days. Receivers, VCRs, and solar chargers were located 5-10 $\mathrm{m}$ away from the nest to minimize disturbance when maintaining equipment or changing tapes.

Grassland nest activity was captured by video systems that included miniature cameras with infrared LEDs (Renfrew and Ribic 2003). Cameras were $64 \mathrm{~cm}^{3}$ and placed $12-25 \mathrm{~cm}$ from a selected nest, depending on nest structure and surrounding vegetation. The field of view at these distances ranged from 414 to $1,320 \mathrm{~cm}^{2}$. Each camera was mounted on a wooden dowel 3-38 cm above the ground. Cameras were typically placed at or below the height of surrounding vegetation, to avoid creating a visual cue for potential predators. We used digital video recorders (Archos AV500 at 30 frames/sec) attached to cameras with 25-m cables (following the protocol established by Renfrew and Ribic 2003). Batteries and recorders were replaced and nest contents viewed on the recorder every $48 \mathrm{hr}$.

\section{Video Analysis}

We reviewed video from 19 nests: Blue-winged Warbler $(n=2)$, Prairie Warbler $(n=2)$, Indigo Bunting $(n=3)$, and Field Sparrow (Spizella pusilla, $n=1$ ) from shrublands; and Grasshopper Sparrow (Ammodramus savannarum, $n=3$ ), Eastern Meadowlark (Sturnella magna, $n=4$ ), and Bobolink (Dolichonyx oryzivorus, $n=4$ ) from grasslands. Video of shrubland birds was recorded from June through July in 2004-2006; we analyzed approximately $370 \mathrm{hr}$ of video from a total of 37 nights. Video of grassland nests was collected from June through July in 2009-2010; we analyzed $352 \mathrm{hr}$ of video from 48 nights. For each nest, we concluded the review of video at the point where the brood size changed (e.g., any nestling was depredated or fledged).

All study species we videoed are sexually monomorphic except the Prairie Warbler, Indigo Bunting, and Bobolink. For monomorphic species, 

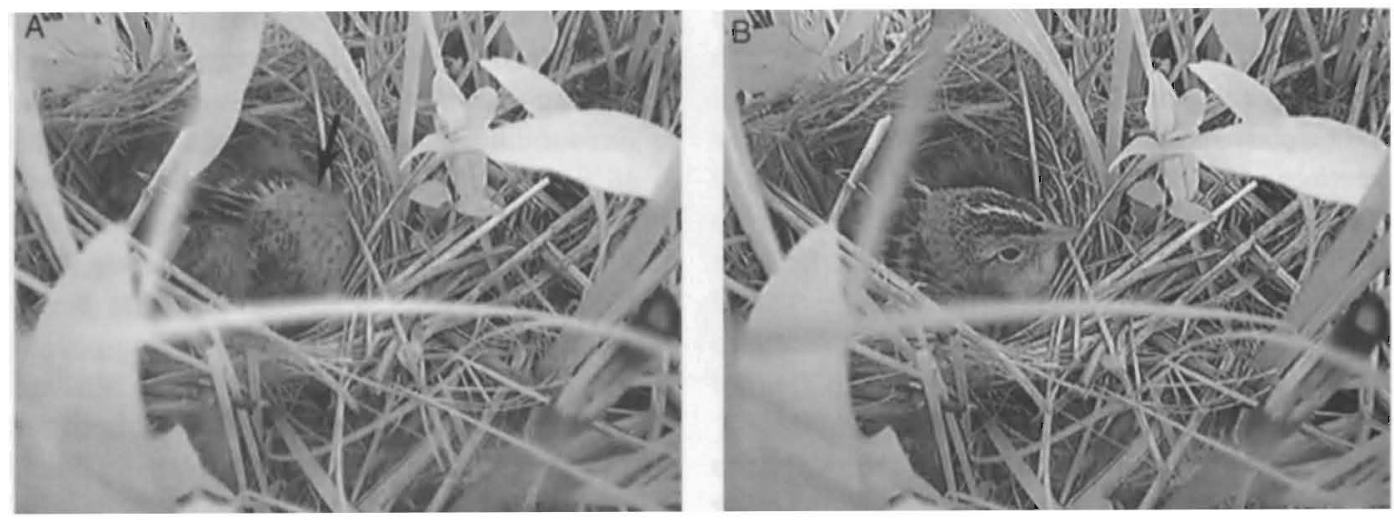

Figure 9.1. Typical postures of an adult passerine (a) in back sleep, with head turned to one side and bill tucked under scapular feathers (top of head indicated by arrow), and (b) vigilant while brooding young. These images of a Grasshopper Sparrow in southwestern Wisconsin were taken at $9 \mathrm{~min}$ and $6 \mathrm{~min}$ prior to sunrise, respectively.

we presumed that only females brooded during the night based on our observations of dimorphic passerine species. Shrubland species were banded, confirming that females had brood patches while males did not, thus making male brooding less plausible. Yet we cannot be certain that male or non-parental brooding did not occur in monomorphic species, as this has been documented in Grasshopper Sparrow (Kaspari and O'Leary 1988).

When reviewing video, we used the bird's head position to define behavior. We defined back sleep to be when the head was turned to the side toward the wing with the bill tucked under or on the scapular feathers (Fig. 9.1a). We defined a vigil to be when the head was facing forward and moving or facing forward with at least one eye open (Fig. 9.1b). Our definition of a vigil differs from other studies of vigilant sleep or scans because our definition included a change in head position (Lendrem 1983). Duration of short vigils could not always be determined for the shrubland birds due to video recording speed and distance of the camera from the nest, so the duration of vigils was not estimated as sampling would have been biased toward longer vigils. We also determined whether or not a bird exhibited front sleep-like behavior, where the head was forward but the bill was down near the breast of the bird and the head was not moving. Because a bird could open and close its eyes while maintaining the bill-down position and we could not reliably see both eyes on the video, we could not differentiate between front sleep (both eyes shut) and unihemispheric or vigilant sleep (one eye open). It also could be difficult to determine transitions between a vigil and front sleep-like behavior. We therefore measured duration of front sleep-like behavior, not individual bouts.

Times were recorded for several events: (1) when the female returned to the nest for the night, (2) the first back sleep of the night, (3) the first front sleep-like behavior of the night, (4) the last vigil before departing the nest in the morning, and (5) the time of the first nestling feeding in the morning. To standardize times, we converted all observations to be relative to local sunrise and sunset. We used annual sunrise and sunset data from the U.S. Naval Observatory Astronomical Applications Department (2011). We calculated duration of back sleep bouts, duration of front sleep-like behavior, and duration of first foraging. Duration of a back sleep bout was the time from the beginning of back sleep to the beginning of the next vigil (i.e., bird moved head into a forward position). Duration of front sleep-like behavior was the time from the first front sleep-like behavior to back sleep. Duration of first foraging was the time from first leaving the nest in the morning to the first feeding of nestlings.

Data were summarized by individual. For behaviors that were measured only once per night, we averaged the data over nights watched for the individual. To obtain the average duration of back sleep bouts for an individual, we first averaged the duration of bouts per night and then averaged over nights. We report mean duration and standard error of behaviors by species. We evaluated whether behaviors varied first by group (grassland or shrubland) and then among all species using a Kruskal-Wallis test (Conover 1999); trends were assessed at an alpha 
of 0.10 and significance at 0.05 . Field Sparrows were not included in the tests because our video sampling was limited to one nest.

Because parameters of sleep are likely correlated with energetics (Lima et al. 2005) and body size (Weathers 1992), we used Spearman's rank correlation (Conover 1999) (again excluding the one Field Sparrow nest) to test for general trends in aspects of nocturnal behavior among species. We used estimates of body mass based on information in Birds of North America species accounts (Poole 2005). Our general assumptions were that (1) larger species (by mass) would spend more time on the nest due to relatively lower thermal and energetic constraints imposed by their young (Weathers 1992) and (2) waking time would be related to body size (Thomas et al. 2002).

\section{RESULTS}

The analyzed shrubland species (Blue-winged Warbler, Prairie Warbler, and Indigo Bunting) all made their final return to the nest at about the same time $(K W=2.5, P>0.10)$, around sunset (Table 9.1). In contrast, grassland species differed from each other $(\mathrm{KW}=6.7, P<0.05)$; Eastern Meadowlark returned the earliest before sunset and Grasshopper Sparrow returned the latest after sunset (Table 9.1). This difference among the grassland species resulted in a difference in final return time when testing across all species $(K W=12.4, P<0.05)$. For all species, the last nestling feeding at night generally corresponded with the female's final evening trip to the nest. Exceptions were rare. In one instance, a Bobolink male returned to feed the chicks after the female had settled on the nest for the night; at a second Bobolink nest, the female did not feed the chicks, returning to the nest for the night $1 \mathrm{~min}$ after the male had fed the chicks. The shrubland birds were asleep (back sleep position) within 20-50 min of their return $(K W=2.8, P>0.10)$ (Table 9.1). For grassland species, Eastern Meadowlark took about four times longer to sleep (back sleep position) than Grasshopper Sparrow ( $K W=5.8$, $P<0.05$ ) (Table 9.1). Overall, however, time to sleep was not different among species $(K W=4.8$, $P>0.10)$.

All species exhibited back sleep posture, with average sleep bout duration varying from $6 \mathrm{~min}$ (Grasshopper Sparrow) to $28 \mathrm{~min}$ (Blue-winged Warbler, Field Sparrow) (Table 9.1). Within the shrubland species, Prairie Warbler had a tendency for shorter sleep bout duration compared to Blue-winged Warbler and Indigo Bunting $(\mathrm{KW}=$ 4.5, $P=0.10)$. Grassland species did not differ in average duration of back sleep bouts $(K W=2.0$, $P>0.10)$ due to individual variability in Eastern Meadowlark and Bobolink (Table 9.1). Specifically, one Eastern Meadowlark had a mean bout duration of $4.5 \mathrm{~min}$ while a second averaged $23.2 \mathrm{~min}$; one Bobolink had a mean bout duration of $6 \mathrm{~min}$, while a second averaged $25 \mathrm{~min}$. Mean duration of back sleep bouts did not differ among species $(K W=8.7, P>0.10)$. Front sleep behavior was only observed in two individuals of two grassland species and always preceded back sleep. During two of four nights, one Grasshopper Sparrow spent $6 \mathrm{hr} 28 \mathrm{~min}$ (duration on nest was $8 \mathrm{hr}$ $11 \mathrm{~min}$ ) and $5 \mathrm{hr} 3 \mathrm{~min}$ (duration on nest was $7 \mathrm{hr}$ $58 \mathrm{~min}$ ) alternating between front sleep behavior and waking before back sleep occurred. During two of five nights, one Eastern Meadowlark spent $5 \mathrm{hr} 44 \mathrm{~min}$ ( $8 \mathrm{hr} 24$ min duration on nest) and $6 \mathrm{hr} 9 \mathrm{~min}$ (9 hr 55 min duration on nest) alternating between front sleep behavior and waking before back sleep occurred.

Regardless of back or front position, sleep was interrupted throughout the night for all species except Blue-winged Warbler, which had vigils primarily before midnight and less frequently in the hours before sunrise. In some instances, insects or arthropods interrupted the birds' sleep; in other cases, the birds were undisturbed by the presence of invertebrates. At two nests, female Indigo Buntings appeared to be awakened on multiple occasions by the presence of numerous mosquitoes seen on video, as evidenced by the female shaking her body and moving her bill over her feathers. Similarly, a sleeping Bobolink and Grasshopper Sparrow became alert when a spider moved across their bodies; the Grasshopper Sparrow consumed the spider.

Weather also affected nocturnal behaviors in several cases. In three instances, two Grasshopper Sparrows and a Bobolink remained awake with both eyes open for over $2 \mathrm{hr}$ staring upward as a thunderstorm moved through. During rain events at two other nests, a Prairie Warbler and an Indigo Bunting had nocturnal vigils lasting over $2 \mathrm{hr}$ and stayed on the nest up to $1 \mathrm{hr}$ longer than average before first leaving to forage for nestlings. In these cases, the females stayed awake and brooded, presumably to protect nestlings from rain. 
TABLE 9.1

Timing and duration of nocturnal behaviors of passerine adults at nests during the nestling stage.

\begin{tabular}{|c|c|c|c|c|c|c|}
\hline Species & $\begin{array}{l}\text { Estimated } \\
\text { body mass } \\
\text { (g) }\end{array}$ & Nests & $\begin{array}{l}\text { Nights } \\
\text { observed }\end{array}$ & $\begin{array}{l}\text { Mean final return } \\
\text { time to nest (SE) } \\
\text { (decimal min) }\end{array}$ & $\begin{array}{l}\text { Mean duration awake on } \\
\text { nest before first back sleep } \\
\text { (SE) (decimal min) }\end{array}$ & $\begin{array}{c}\text { Mean duration of back } \\
\text { sleep bouts (SE) } \\
\text { (decimal min) }\end{array}$ \\
\hline \multicolumn{7}{|l|}{ Shrubland } \\
\hline $\begin{array}{l}\text { Blue-winged Warbler } \\
\text { (Vermivora pinus) }\end{array}$ & 8.5 & 2 & 7 & $-5.0(3.6)$ & $48.4(8.1)$ & $27.6(5.4)$ \\
\hline $\begin{array}{l}\text { Prairie Warbler } \\
\text { (Setophaga discolor) }\end{array}$ & 7.7 & 2 & 5 & $4.0(3.2)$ & $22.3(8.1)$ & $11.9(0.7)$ \\
\hline $\begin{array}{l}\text { Indigo Bunting } \\
\text { (Passerina cyanea) }\end{array}$ & 14.5 & 3 & 16 & $1.5(2.8)$ & $37.4(9.2)$ & $21.3(4.5)$ \\
\hline $\begin{array}{l}\text { Field Sparrow } \\
\text { (Spizella pusilla) }\end{array}$ & 12.5 & 1 & 2 & -5.5 & 25.3 & 27.4 \\
\hline \multicolumn{7}{|l|}{ Grassland } \\
\hline $\begin{array}{l}\text { Grasshopper Sparrow } \\
\text { (Ammodramus savannarum) }\end{array}$ & 17 & 3 & 10 & $18.2(2.5)$ & $10.0(2.2)$ & $5.8(0.5)$ \\
\hline $\begin{array}{l}\text { Eastern Meadowlark } \\
\text { (Sturnella magna) }\end{array}$ & 90 & 4 & 11 & $-8.8(7.0)$ & $46.6(14.8)$ & $13.9(4.1)$ \\
\hline $\begin{array}{l}\text { Bobolink } \\
\text { (Dolichonyx oryzivorus) }\end{array}$ & 43 & 4 & 21 & $11.4(3.5)$ & $11.7(2.1)$ & $11.8(4.6)$ \\
\hline
\end{tabular}

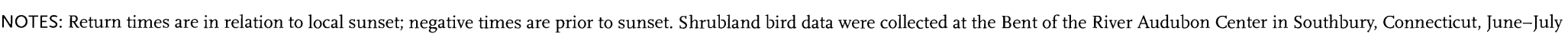

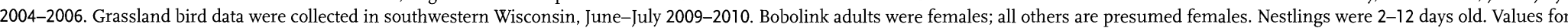
body mass were estimated from information in Birds of North America species accounts (Poole 2005). 
Movement of nestlings appeared to wake the females from sleep, particularly toward the end of the nestling period. In these cases, females repositioned young underneath them during the night and were visibly "bumped" or raised up and down by nestlings underneath. A Bluewinged Warbler with four nestlings (one a Brown-headed Cowbird, Molothrus ater) was repeatedly bumped completely above the nest rim toward the end of the nestling period. In one extreme instance a Bobolink female in back sleep was pushed out of the nest and, in a separate back sleep bout, was upended by chick activity. Some females did not stay on the nest toward the end of the nestling period. One Blue-winged Warbler and one Eastern Meadowlark did not stay on the nest the last two nights prior to fledging, one Bobolink female did not stay on the nest the last night before fledging, and one Eastern Meadowlark female did not stay on the nest the third night and last night prior to fledging. In all cases, an adult returned to feed the chicks in the morning.

Shifts in orientation on the nest were few, averaging 0-1.4 shifts per species per night. Bluewinged Warblers, Prairie Warblers, Bobolinks, and Grasshopper Sparrows changed the direction they faced on the nest over the nestling period but usually faced the same direction for an entire night. Indigo Buntings changed sleeping directions $1-6$ times during a single night. The Field Sparrow and Eastern Meadowlarks faced one direction all night, every night for the duration of the study.

On average, the adults woke in the morning (the last waking before departing the nest) around the same time $(P>0.10$, all tests $)$, about 20-30 min before sunrise (Table 9.2). The timing of the last waking before departing the nest was negatively correlated with body size $\left(r_{s}=\right.$ $-0.77)$. Mean overnight duration on the nest (time from final return to nest for the night to time of first flight in the morning) for each species ranged from $6.39 \mathrm{hr}$ (Field Sparrow) to $8.79 \mathrm{hr}$ (Indigo Bunting) (Table 9.2). Mean overnight duration on the nest was positively correlated with body size $\left(r_{s}=0.54\right)$. Shrubland species spent similar durations on the nest (7-9 hr) $(K W=1.6, P>0.10)$. For grassland birds, Eastern Meadowlark spent more time on the nest at night than Grasshopper Sparrow $(K W=7.2, P<0.05)$ (Table 9.2). Some differences between species may be due to the fact that two of three Grasshopper Sparrows appeared to be startled off their nests during the night, resulting in durations on the nest for those nights of a bit over $7 \mathrm{hr}$.

After waking in the morning, shrubland species stayed awake on the nest about 10-20 min (on average) before leaving ( $K W=0.7, P>$ 0.10) (Table 9.2). For grassland species, Eastern Meadowlark stayed awake almost three times longer than Bobolink before leaving the nest $(K W=5.7, P<0.05)$ (Table 9.2). However, when all species were combined, there was no difference in duration awake on the nest before leaving in the morning ( $K W=7.4, P>0.10)$. There was also little relationship between body size and time of departure $\left(r_{s}=0.26\right)$. The first absence from the nest in the morning was short for all species $(P>0.10$, all tests $)$ and on average nestlings were fed within $12 \mathrm{~min}$ of a parent's departure (Table 9.2). Shrubland species did not differ significantly $(K W=4.5$, $P=0.10$ ) in time of first nestling feeding; however, Prairie Warbler tended to return to feed nestlings just before sunrise, whereas the other two shrubland species fed after sunrise (Table 9.2). There was more variability in first feeding times among grassland species, but there was also more individual variation within species (Table 9.2); thus, we found no evidence that the grassland species first fed nestlings at different times $(K W=3.8, P>0.10)$. Among all species, Bobolink tended to first feed nestlings before sunrise, while Blue-winged Warbler and Indigo Bunting returned after sunrise to feed their nestlings $(K W=9.5,0.05<P<0.10)$. Male Bobolinks from three of four nests were the first to feed their nestlings after the females left the nest, feeding on average $54 \mathrm{sec}$ before the female did ( $\mathrm{SE}=20 \mathrm{sec}, n=4)$. In contrast, all Blue-winged Warbler males arrived at the nest before the females' first morning flight and followed the females leaving the nest so that the sex of the parent delivering the first feeding could not be determined. Therefore, the first feeding in the morning could have been delivered by either sex among the sexually monomorphic species. 
TABLE 9.2

Early morning behaviors of passerine adults at nests during the nestling stage.

\begin{tabular}{|c|c|c|c|c|c|c|}
\hline Species & $\begin{array}{l}\text { Mean waking time } \\
\text { (SE) (decimal min) }\end{array}$ & $\begin{array}{l}\text { Mean duration } \\
\text { awake on nest prior } \\
\text { to departure (SE) } \\
\text { (decimal min) }\end{array}$ & $\begin{array}{c}\text { Mean first } \\
\text { departure time } \\
\text { (SE) (decimal min) }\end{array}$ & $\begin{array}{l}\text { Mean duration on } \\
\text { nest from final } \\
\text { evening return to } \\
\text { first morning } \\
\text { departure (SE) } \\
\text { (decimal hr) }\end{array}$ & $\begin{array}{l}\text { Mean duration of } \\
\text { first departure (SE) } \\
\text { (decimal min) }\end{array}$ & $\begin{array}{c}\text { Mean first feeding } \\
\text { time (SE) } \\
\text { (decimal min) }\end{array}$ \\
\hline Blue-winged Warbler & $-19.0(10.9)$ & $20.1(16.2)$ & $3.3(3.1)$ & $8.13(0.94)$ & $7.4(2.5)$ & $10.7(0.6)$ \\
\hline Prairie Warbler & $-21.0(2.6)$ & $10.4(4.1)$ & $-10.5(6.7)$ & $7.36(1.42)$ & $7.0(3.1)$ & $-3.6(3.6)$ \\
\hline Indigo Bunting & $-26.9(6.0)$ & $22.0(6.4)$ & $-6.2(4.0)$ & $8.79(0.28)$ & $11.4(3.6)$ & $5.2(2.5)$ \\
\hline Field Sparrow & -3.3 & 23.1 & 19.7 & 6.39 & 8.2 & 27.9 \\
\hline Grasshopper Sparrow & $-25.5(12.7)$ & $15.2(7.5)$ & $-15.2(12.7)$ & $8.04(0.25)$ & $4.1(2.2)$ & $-5.8(7.7)$ \\
\hline Eastern Meadowlark & $-31.8(5.0)$ & $28.4(6.3)$ & $1.9(5.9)$ & $8.73(0.06)$ & $11.0(1.7)$ & $7.7(6.8)$ \\
\hline Bobolink & $-25.8(5.6)$ & $8.8(0.9)$ & $-13.3(3.8)$ & $8.29(0.04)$ & $5.7(1.7)$ & $-10.7(4.6)$ \\
\hline
\end{tabular}

NOTES: Times are in relation to local sunrise; negative times are prior to sunrise. Shrubland bird data were collected at the Bent of the River Audubon Center in Southbury, Connecticut, June-July 2004-2006. Grassland bird data were collected in southwestern Wisconsin, June-July 2009-2010. Bobolink adults were females; all others are presumed females. Nestlings were 2-12 days old. 


\section{DISCUSSION}

Though our study was small in scope, it is the first to describe nocturnal behaviors of passerine species in shrubland and grassland habitats, and potential species differences. Most species, regardless of habitat, exhibited similar patterns in behavior near sunset, during the night, and near sunrise. General trends were found for total sleep duration and time of waking relative to body size. Results from earlier observational studies of Prairie Warbler and other passerine species are limited but, in general, fell within the ranges we documented for times of final return to the nest in the evening and first departure from the nest in the morning. Nolan (1978) reported Prairie Warbler females with nestlings in Indiana spent a total of $9.25 \mathrm{hr}$ on the nest at night, nearly $2 \mathrm{hr}$ longer than in our study. This difference may reflect variation in day length, weather, or habitat between study sites. During the nestling stage, House Wrens returned to the nest 9.6 min after sunset and departed $5.7 \mathrm{~min}$ before sunrise and Song Sparrows returned $3 \mathrm{~min}$ before to $16 \mathrm{~min}$ after sunset (Kendeigh 1952). For a single nest of Carolina Wren (Thryothorus ludovicianus) during the nestling stage, the female returned to the nest 4 to $17 \mathrm{~min}$ after sunset; a single departure from the nest occurred at $29 \mathrm{~min}$ after sunrise (Nice and Thomas 1948). Great Tits (Parus major major), during the nestling stage, returned to the nest shortly before sunset to after sunset and left the nest 6 min after sunrise (Kluijver 1950). Song Sparrows left the nest between $22 \mathrm{~min}$ to $33 \mathrm{~min}$ before sunrise (Kendeigh 1952), which was earlier than that found for our species. Given the small samples in prior studies (in some cases one observation of one individual), the relatively small variation in timing of behaviors in regard to sunrise and sunset, and the numerous variables that can affect behavior (e.g., cloud cover, temperature, precipitation, and vegetation density), it is difficult to identify species differences in behavior from these studies. Our study identifies some potential species variation in behaviors that needs further exploration.

While we found a relationship between body size and waking time, there was little relationship between size and time of departure. This suggests differences in behavior after waking. Possible explanations may include differences in energetic demands and thermal exposure between habitats and nest structure types (domed or not). Also, brooding females awake on the nest in the morning may be listening to males for information related to reproductive status [some species are polygynous (Indigo Bunting, meadowlarks, Bobolink) and/or are multi-brooded (sparrows and meadowlarks)].

Overall, the pattern of sleeping with vigils that we documented is similar to the pattern found in incubating Mallards (Javurkova et al. 2011). Vigilance may be an adaptation to nocturnal predation pressure. Because grassland and shrubland passerines often experience high nest predation compared to forest species, predation pressure may select for more vigilant behavior of females nesting in grasslands and shrublands (Martin 1993a). Frequent "peeks" decrease the likelihood of a female becoming the victim of predation herself. Ellison and Ribic (chapter 12, this volume) found that there was a greater chance at night than during the day that a female would leave the nest rather than defend it when a snake arrived. The benefits of vigilance for predators may outweigh the costs of interrupted sleep for these species.

Physical disturbance (e.g., insects, weather) and nestling activity affected the sleeping patterns of females with nestlings in our study. Skutch (1989) provided anecdotal evidence that heavy rain can cause brooding adults to remain on the nest later in the morning or return earlier at night. Walkinshaw (1968) reported that while all Field Sparrows brooded on the nest at night through the fourth night, only $50 \%$ were present the fifth night and only $25 \%$ on the sixth night. Late-stage night absence was also noted by Kendeigh (1952) for House Wrens and by Nice and Thomas (1948) for Carolina Wrens. This suggests that disturbance can be too great for some females to sleep on the nest when nestlings are large and active; this might be especially problematic for species with larger brood sizes such as the Blue-winged Warbler or individuals that are parasitized (as cowbird young are often larger than nestlings of host species).

We did not find that any of our species routinely left the nest at night during the nestling stage. This contrasts with the Western Meadowlarks studied by Powell et al. (chapter 5, this volume). Kendeigh (1952) reported that a Song Sparrow left her nestlings for $2 \mathrm{hr} 20 \mathrm{~min}$ in the middle of the night on one occasion; Kendeigh (1952) also 
noted that the thermal sensor indicated that the female was likely perched on the edge of the nest for $45 \mathrm{~min}$ before departing out of range of the sensor.

Though we presumed that only female parents attended the nest at night, it is possible that for monomorphic species, males or non-parental attendants may have brooded. Kaspari and O'Leary (1988) found that $17 \%$ of daytime visits to Grasshopper Sparrow nests $(n=23)$ were by non-parental attendants that carried food and brooded young of unrelated nestlings. Guzy et al. (2002) documented a presumed male helper at a Henslow's Sparrow (Ammodramus henslowii) nest that fed the chicks, though no brooding was observed. Future studies should document adult absences during the night and consider color banding parents to confirm sex and relatedness of nest attendants.

The evolutionary drivers affecting sleep requirements and sleep patterns are largely unstudied for breeding passerines. Predation, as the greatest driver for the evolution of life history traits in birds, has likely affected traits such as nest placement and habitat selection (Martin 1993b). It is also likely that anti-predator nocturnal behaviors have evolved to compensate for different predation pressures, and these hypotheses could be tested in the field using video surveillance.

Technological advances have made smaller, longer-lived batteries, digital data storage, and smaller cameras with better image quality more affordable, enabling field biologists to document behavior and natural history in greater detail than previously possible (Cox et al., chapter 15, this volume). The study of nocturnal behavior is yet another area where the use of video surveillance systems can contribute greatly to our understanding of avian evolution and ecology.

\section{ACKNOWLEDGMENTS}

We thank the field technicians who helped collect the data used in this paper. We thank the staff and volunteers of Audubon Connecticut and Bent of the River Audubon for their resources and support and M. E. Slay and V. Melhart for support and assistance in the field. We thank undergraduates in the Department of Forest and Wildlife Ecology, University of Wisconsin-Madison, for helping to watch the grassland bird videos. C. M. Slay thanks R. A. Askins for advice and C. J. Amlaner for helpful discussions. We thank P. J. Pietz, S. A. Temple, and
L. A. Powell for comments on the manuscript. C. M. Slay dedicates this paper in loving memory of her father, B. Melhart, who designed the shrubland camera system and who always had a creative hand in her science projects. We thank the following organizations for providing funding for the shrubland bird study: Arkansas Audubon Society Trust, Connecticut Audubon Council, Lillinonah Audubon Society, Nuttall Ornithological Club, and Wilson Ornithological Society. We thank the following organizations for providing funding for the grassland bird project: U.S. Department of Agriculture Hatch Grant Program, U.S. Fish and Wildlife Service Region 3 Nongame Bird Conservation Program and Partnerships for Wildlife Program, U.S. Fish and Wildlife Service Federal Aid to Wildlife Restoration Act under Pittman-Robertson Project W-160-P, Wisconsin Department of Natural Resources, and U.S. Geological Survey Wisconsin Cooperative Wildlife Research Unit. Mention of trade names or commercial products does not constitute endorsement for use by the U.S. government. We thank the Department of Forest and Wildlife Ecology, University of Wisconsin, Madison, for assistance with publication expenses.

\section{LITERATURE CITED}

Amlaner, C. J., and N. J. Ball. 1983. A synthesis of sleep in wild birds. Behaviour 87:85-119.

Conover, W. J. 1999. Practical nonparametric statistics. Third edition. John Wiley and Sons, New York, NY.

Fuchs, T., A. Haney, T. J. Jechura, F. R. Moore, and V. P. Bingman. 2006. Daytime naps in night-migrating birds: behavioral adaptation to seasonal sleep deprivation in the Swainson's Thrush, Catharus ustulatus. Animal Behaviour 72:951-958.

Fuchs, T. D. Maury, F. R. Moore, and V. P. Bingman. 2009. Daytime micro-naps in a nocturnal migrant: an EEG analysis. Biology Letters 5:77-80.

Gauthier-Clerc, M., A. Tamisier, and F. Cezilly. 2000. Sleep-vigilance trade-off in Gadwall (Anas strepera) during the winter period. Condor 102:307-313.

Guzy, M., C. A. Ribic, and D. W. Sample. 2002. Helping at a Henslow's Sparrow (Ammodramus henslowii) nest in Wisconsin. Wilson Bulletin 114:407-409.

Javurkova, V., D. Horak, J. Kreisinger, P. Klvana, and T. Albrecht. 2011. Factors affecting sleep/vigilance in incubating Mallards. Ethology 117:345-355.

Kaspari, M., and H. O'Leary. 1988. Nonparental attendants in a north-temperate migrant. Auk 105:792793.

Kendeigh, S. C. 1952. Parental care and its evolution in birds. Illinois Biological Monographs 22:1-356.

Kluijver, H. N. 1950. Daily routines of the Great Tit, Parus m. major L. Ardea 38:99-135. 
Lendrem, D. W. 1983. Sleeping and vigilance in birds, I: Field observations of the Mallard (Anas platyrhynchos). Animal Behaviour 31:532-538.

Lendrem, D. W. 1984. Sleeping and vigilance in birds, II: An experimental study of the Barbary Dove (Streptopelia risoria). Animal Behaviour 32:243-248.

Lima, S. L., N. C. Rattenborg, J. A. Lesku, and C. J. Amlaner. 2005. Sleeping under the risk of predation. Animal Behaviour 70:723-736.

Martin, T. E. 1993a. Nest predation among vegetation layers and habitats: revising the dogmas. American Naturalist 141:897-913.

Martin, T. E. 1993b. Nest predation and nest sites. BioScience 43:523-532.

Nice, M. M., and R. H. Thomas. 1948. A nesting of the Carolina Wren. Wilson Bulletin 60:139-158.

Nolan, V. 1978. The ecology and behavior of the Prairie Warbler Dendroica discolor. Ornithological Monographs 26:1-595.

Poole, A. (editor). 2005. The Birds of North America online. <http://bna.birds.cornell.edu/BNA/> May 2011).

Rattenborg, N. C., S. L. Lima, and C. J. Amlaner. 1999. Half-awake to the risk of predation. Nature 397:397-398.

Rattenborg, N. C., S. L. Lima, and C. J. Amlaner. 2000. Behavioral, neurophysiological and evolutionary perspectives on unihemispheric sleep. Neuroscience and Biobehavioral Reviews 24:817-842.

Renfrew, R. B., and C. A. Ribic. 2003. Grassland passerine nest predators near pasture edges identified on videotape. Auk 120:371-383.

Roth, T. C., II, J. A. Lesku, C. J. Amlaner, and S. L. Lima. 2006. A phylogenetic analysis of the correlates of sleep in birds. Journal of Sleep Research 15:395-402.
Skutch, A. R. 1989. Birds asleep. University of Texas Press, Austin, TX.

Slay, C. M., and K. G. Smith. 2009. A comparison of nest success rates of four shrubland specialists in conservation managed fields to other managed and unmanaged shrublands. Pp. 705-712 in T. Rich, C. Arizmendi, C. Thompson, and D. Demarest (editors), Tundra to tropics: connecting birds, habitats, and people. Proceedings of the Fourth International Partners in Flight Conference, Partners in Flight, McAllen, TX.

Thomas, R. J., T. S. Székely, I. C. Cuthill, D. G. C. Harper, S. E. Newson, T. D. Frayling, and P. D. Wallis. 2002. Eye size in birds and the timing of song at dawn. Proceedings of the Royal Society of London, Series B 269:831-837.

Thompson, F. R., III, W. Dijak, and D. E. Burhans. 1999. Video identification of predators at songbird nests in old fields. Auk 116:259-264.

U.S. Naval Observatory Astronomical Applications Department. 2011. Sun or moon rise/set for one year. $<$ http://aa.usno.navy.mil/data/docs/RS_OneYear .php> (5 May 2011).

Walkinshaw, L. H. 1968. Eastern Field Sparrow. Pp. 1217-1235 in O. L. Austin (editor), Life histories of North American cardinals, grosbeaks, buntings, towhees, finches, sparrows, and allies. U.S. National Museum Bulletin No. 237.

Weathers, W. W. 1992. Scaling nestling energy requirements. Ibis 134:142-153.

Weeden, J. S. 1966. Diurnal rhythm of attentiveness of incubating female Tree Sparrows (Spizella arborea) at a northern latitude. Auk 83:368-388.

Wellmann, A. E., and C. T. Downs. 2009. A behavioural study of sleep patterns in the Malachite Sunbird, Cape White-eye and Fan-tailed Widowbird. Animal Behaviour 77:61-66. 